\title{
Cavete collegae
}

$\mathrm{H}+$ hat begonnen, Arztpraxen die Anerkennung für den Betrieb von Praxisoperationssälen auszusprechen. Wir halten folgende Punkte fest:

- H+ ist weder vertraglich noch gesetzlich legitimiert, solche Anerkennungen auszusprechen. Sie sind damit nichtig.

- Anträge sind an die FMH zu richten. Über die Anerkennung wird im vertraglich vorgesehenen, von den vier Vertragsparteien FMH, H+, santésuisse und MTK gebildeten Gremium entschieden.

- Die H+ verlangt für den Eintrag in ihre Datenbank Fr. 500.-. Diese können nicht als Vorleistung für die Zertifizierung gemäss Punkt 2 betrachtet werden; die Rechnungs- stellung für die rechtsgültige Anerkennung erfolgt hier (zusätzlich) separat. Der Verweis auf Gebühren der FMH ist unzutreffend und irreführend.

- Die Antragsteller werden von H+ eingeladen, Mitglied von $\mathrm{H}+\mathrm{zu}$ werden. Wir überlassen unseren Mitgliedern den Entscheid darüber, ob sie ihre Interessen bei dieser Organisation vertreten sehen. Wir verweisen in diesem Zusammenhang auf verschiedene Publikationen in diesem Blatt, vor allem auch auf die bald erscheinenden Informationen zu RE II.

Verbindung der Schweizer Ärztinnen und Ärzte FMH

\section{Cavete collegae}

Depuis peu, $\mathrm{H}+$ délivre une reconnaissance pour l'exploitation de salles d'opération en cabinet privé. A cet égard, nous retenons les points suivants:

- Aucune disposition légale ou contractuelle ne donne à $\mathrm{H}+$ la légitimation de prononcer de telles reconnaissances, lesquelles sont donc caduques.

- Les demandes doivent être adressées à la FMH. Conformément à l'accord conclu entre la FMH, H+, Santésuisse et la CTM, la reconnaissance est prononcée par un organe composé de représentants des quatre parties contractantes.

- H+ facture Fr. 500.- pour l'enregistrement dans sa banque de données. Ce montant ne peut pas être considéré comme avance pour la certification réalisée selon le point 2; la facturation pour une reconnaissance présentant toute la validité requise est effectuée ici de manière séparée (de surcroît). La mention des taxes de la FMH est incorrecte et prête à confusion.

- H+ invite les candidats à s'affilier à H+. Nous laissons le soin à nos membres de voir s'ils trouvent un intérêt à s'affilier à cette organisation. Dans ce contexte, nous vous renvoyons aux différents articles publiés dans notre magazine, en particulier aussi aux informations qui seront publiées prochainement sur la phase de remaniement II du TARMED.

Fédération des médecins suisses FMH 